\title{
The importance of sensorial empathy and the language of touch when crafting textiles for people who are visually impaired
}

\section{Keywords}

empathy

senses

blindness

visual impairment

health

well-being

textiles

craft

\begin{abstract}
This article reflects upon a pilot project crafting textile samples/prototypes for people who are visually impaired. It explores the role that sensorial empathy and further understanding of the language of touch play in the textile crafting process for makers working with people who are visually impaired, and that aesthetic and experiential textiles (while important to all) are especially important to people who are visually impaired. The project undertakes craft research in an area that is generally overlooked by textile designers. The makers/ participants were sighted second-year undergraduate textile design students at Nottingham Trent University and the end users, who acted as informants, were service users at My Sight Nottinghamshire (a charity in the United Kingdom addressing visual impairment). The project is situated within human-centred design, with a focus on physically intuitive designs crafted for people with visual impairments. The application and usage of the samples/prototypes are aimed at inclusivity, with engagement centred primarily around haptic
\end{abstract}


touch, and so looking at the textiles may not reveal their potential application, which becomes more apparent through physical engagement. The project was inspired by work within sensory studies, including the concept of sensorial empathy, and research relating to the language of touch through tactile encounters with art objects from a visually impaired perspective. The methods used in the project drew upon empathic design processes, which were informed by sensory ethnography - particularly 'emplacement' and the holistic consideration of mind, body and place - and selected aspects of social haptics, particularly 'environmental description'. Recommendations include further development of the language of touch to support textile craft when working with people who are visually impaired and further consideration of 'grounding' as a concept regularly described by the informants.

\section{Introduction}

The My Sight Nottinghamshire (henceforth My Sight) 'live' project was an opportunity to undertake craft research through textile design with a specific focus on understanding and responding to the tactile (and other sensory) preferences and needs of people who are visually impaired. This is an area of craft research that is generally overlooked by textile designers and often tends to be serviced by specialist (safety) equipment that emphasizes functionality while showing limited interest in the aesthetic concerns of the user. By working directly with the My Sight organization the project benefitted from personal insights and close engagement with the intended end users of the textile designs, who made it clear that they placed high value upon the aesthetically pleasing qualities of the work notably its tactile and visual appeal - and its functionality. The project was undertaken by second-year undergraduate textile design students at Nottingham Trent University (NTU) and was initially inspired by the 'sensorial revolution' encouraged by, among others, the work of David Howes (2006, 2005, 1991), Constance Classen (2012, 2002) and Kathryn Geurts (2002, 2005); crossmodal sensory thinking in the philosophy of Michel Serres (2016); and Laura Marks' work on haptic visuality within film (2000), which has been described as 'the metaphorical caressing of the surface of an object' (Lee in Bristow 2012: 45). Following an exploration of theoretical ideas relating to cross-sensory transfer across media (Hunt 2018), which analysed physical fashion and textile designs influenced by a representation of blindness in a fictional film, the My Sight project was developed to help explore and inform practice-based textile making when designing for people who are visually impaired.

A significant reference point for the project came from Maxine Bristow's work, which has previously explored a similar theoretical lineage to contextualize and discuss textile design practice. Bristow's 'Continuity of touch - textile as silent witness' (2012) describes textiles as an often unseen and overlooked, yet fundamental, aspect of everyday life and the built environment. Part of this 'invisibility' is attributed to the cultural hierarchy of the senses and a tendency to sideline touch as a 
way of knowing (Hemmings 2012: 44). By developing a project where touch, as one form of haptic knowing, was foregrounded above sight we challenged the students to engage more closely (as makers) with human-centred design (Giacomin 2015), focusing upon sensory design (Heywood 2017; Lupton and Lipps 2018) and empathic design (Mattelmaki et al. 2014; Koskinen et al. 2003; Leonard and Rayport 1997). Outcomes from the project were determined, in part, through direct consultation and discussion with visually impaired informants. The informants, in this pilot project, were also the intended end users of the prototypes.

The My Sight project was supported by an NTU External Engagement fund under the 'Enriching Society' research and innovation theme. The project brief was to craft textiles in keeping with the Enriching Society theme, which is inherently aligned with a health and well-being focus; this included the potential to enhance well-being through mood and sensation (such as prototypes that delivered a calming or relaxing affect) and through more practical applications to support or enhance day-to-day activities (such as prototypes to prevent objects from slipping, thereby making simple tasks or activities easier, and less stressful, to manage). The aesthetic appeal of the textiles was also highly important, moving beyond 'ocularcentric' (Jay 1993) and 'ocularnormative' (d'Evie and Kleege 2018) cultural tendencies to consider a more inclusive understanding of sensory perception that was primarily informed by haptic touch.

Even though touch was foregrounded, visual aesthetic appeal retained strong significance because 'it is very rare that anyone is totally blind [within the conventional, medically assessed definitions of the term] and it is much more common to have a small amount of light perception' (Hayhoe 2008: 29) as a form of residual vision. As Georgina Kleege explains in More Than Meets the Eye (2018), the general perception that 'visual impairment' means 'blindness' and blindness means living in complete darkness is misleading; total congenital blindness is a rare occurrence in the industrialized world and only around three in 10,000 births have no visual perception (Kleege 2018). Furthermore, the project recognizes the fundamentally multimodal processes at work when crafting textile designs (especially the impact of increased reliance upon tactile communication and description when working with people who are visually impaired), including the complexities of multisensory processing and the social and materially mediated meanings that inform sense making (Groth 2017); however, the central focus on haptic touch was necessary to provide a clear brief for the students within the limited time frame of the project.

\section{Participants and informants}

Fifteen student participants (from a year group of 68) selected the My Sight project (from a series of three projects) after an initial briefing. The project had a cap of sixteen students as the upper limit, fixed in agreement with My Sight as a manageable number of participants, and so fifteen was ideal because 


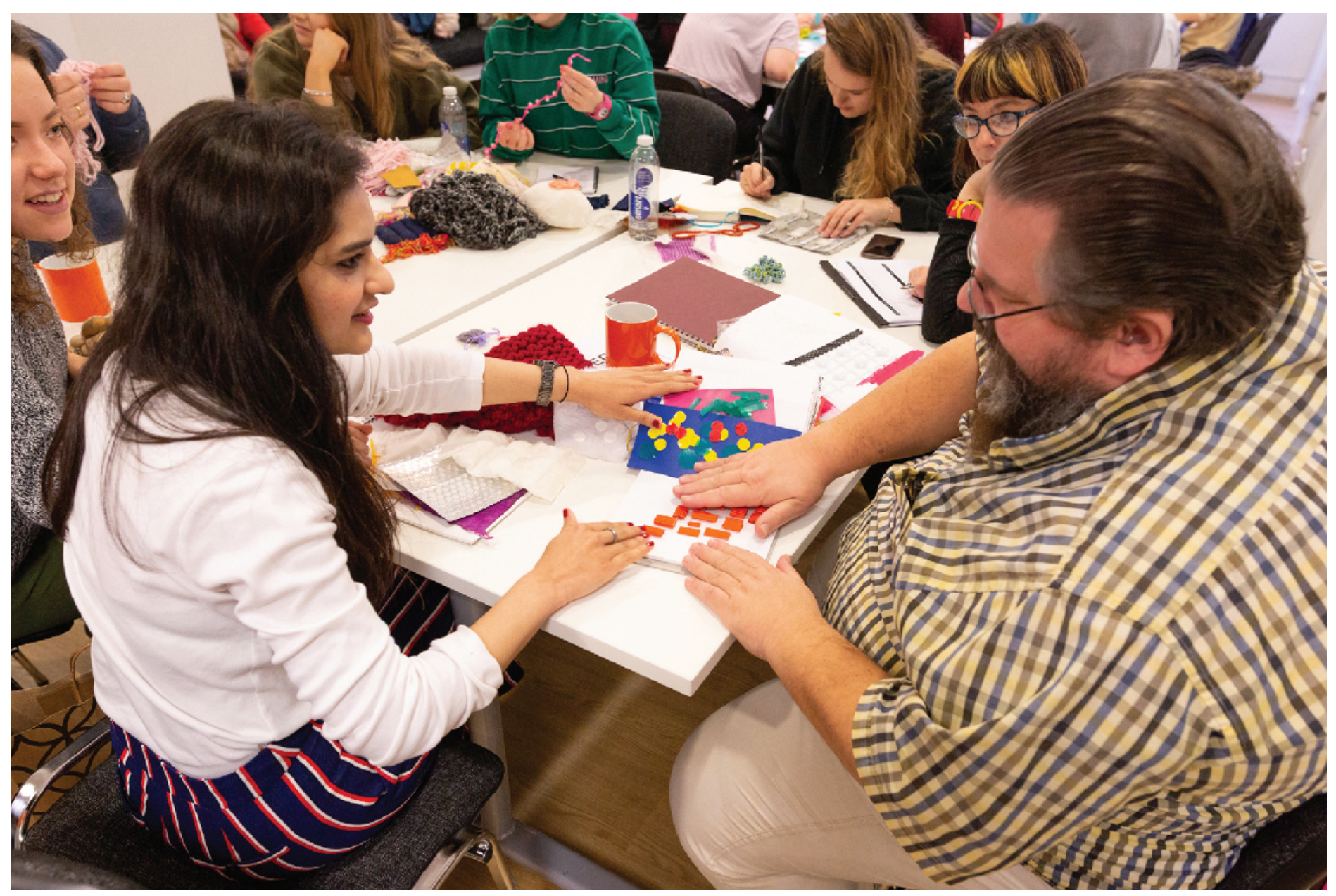

Figure 1: My Sight informant, Rob, with participants, Sakshi and Laura, handling samples and discussing textile design concepts and preferences. ๑ NTU, photographer Mike Kane 2019. 
it allowed organization of the students into three teams each composed of five textile designers. The project ran for approximately three months, starting from the briefing in early November 2018 through to the completion of work in early February 2019. The textile design students were all sighted (without any significant level of visual impairment beyond wearing glasses/contact lenses) and this was their first 'live' project (a project working on a brief set by an 'real-world' company or institution, external to NTU). All the students were female, which reflects a gender bias within textile design course applicants and recruitment rather than any specific gender association within the project.

Nine service users from My Sight agreed to take part in the project - three men and six women - to act as informants (Figure 1). The informants were all adults and varied in age; however, only one informant was between 18 and 30 years of age and the majority were in their 50s or older. The informants also had a range of visual impairments and sight-loss-related conditions; in some cases this included other significant health conditions or complications such as autism or cerebral palsy. The informants' experiences of sight loss and low-level vision were therefore highly variable, affected by the following conditions:

- macular degeneration

- cataracts, diabetic retinopathy and macular degeneration

- nystagmus (involuntary movement in the eyes)

- ushers syndrome (the informant was born deaf and then later developed vision loss caused by retinitis pigmentosa, resulting in tunnel vision)

- septo-optic dysplasia (the informant's optic nerves did not develop normally in utero, resulting in being blind since birth, with limited light perception in one eye)

- degenerative myopia

- congenital blindness (underdevelopment of the eyes, with a limited level of light perception in one eye).

The phrase 'people who are visually impaired' was agreed with My Sight as the preferred term of reference for informants because it places the person before the disability. In the context of this project, the term 'visually impaired' (or 'visual impairment') is based upon the World Health Organisation (WHO 2019) classification for distance vision impairment, which falls into four categories; the informants in the My Sight project typically belonged to one of the latter two categories:

1. Mild: presenting visual acuity worse than $6 / 12$

2. Moderate: presenting visual acuity worse than $6 / 18$

3. Severe: presenting visual acuity worse than $6 / 60$

4. Blindness: presenting visual acuity worse than $3 / 60$. 
Everyone who took part was given an information sheet and asked to sign an ethical consent form. In addition to their willingness to take part, participants and informants also consented to be quoted in research articles (with one exception), to be referred to by their first name (when appropriate) and to feature in photographs taken during the project for use in research presentations and publications (with one exception). The information sheets and consent forms were provided in a range of formats (to be used in combination wherever desirable), including large print, braille and audio description. The aim and organization of the project were also verbally described in group discussions followed by questions and answers.

\section{Project description and textile team concepts}

The project brief required each team to develop a design concept in response to the theme of 'Enriching Society', showing understanding of touch-led sensory engagement that was also combined (where appropriate) with visual contrasts and other sensory considerations. The project brief suggested three potential areas for the teams to focus on:

1. interactive interior soft furnishings and/or wall-based artworks

2. interactive books or toys for children who are visually impaired

3. interactive exhibition pieces to teach sighted adults about visual impairments.

However, these suggestions were planned to be mutable, following discussions and description (including tactile description) of concept ideas and development between the participants (students) and the informants (My Sight service users). Each team was required to show empathy with visual impairment, creative sensory engagement and understanding of tactile communication based on four key criteria:

1. enriching lives

2. empathizing with visual impairment

3. sensory richness of design

4. foregrounding tactile communication.

The students each drew upon their personal textile specialism from embroidery, print, weave or knit to produce a series of at least six to eight prototypes each, whilst also working with their team to undertake shared contextual and market research. Each team developed a shared group concept and colour palette to make their prototypes coherent as a team outcome, with the requirement of producing twelve final innovative samples for presentation upon completion of the project. From a 
pedagogical perspective, an additional objective was for the participants to learn from people who are visually impaired and for that learning process to influence their design thinking and engagement with materials as textile makers. All three teams chose to focus on aspects of interior design and handheld pieces for everyday use. Their respective team concepts were Textural Dialogue, Sensory Vision and Inverted Environment.

The Textural Dialogue team (Grace, Kate, Hannah, Janna and Dory) included three Embroidery and two Weave students. Their purpose-led concept used familiar haptic touch reference points from the urban environment, such as raised corduroy lines and blister bumps on paving slabs, as a starting point for the development of a tactile and visual language within interior spaces. From the beginning of the project the students recognized the importance of bodily knowing, both to imagine craft responses to the project brief and to help inform their choices and use of materials - an approach that Camilla Groth identifies within her research into embodied cognition as relating to both'representational' and 'non-representational' modes of craft and design practice (2017: 62-63). Woven construction, cutting, stitch, layering, beaded embellishment and material manipulation (Figure 2) were juxtaposed to generate contrasting textures and surface qualities (hard/soft, smooth/rough, flexible/rigid, cold/warm). This range of tactile sensory experiences was combined with specific colour choices, which were bold (to enable high contrast) and with minimal tonal variations (for ease of recognition). Each colour choice was associated with a specific kind of surface or texture with potential (when used strategically within interior space) to indicate direction, provide warning, alert the user to differentiation between environments/areas and other signifiers of guidance or change (e.g. raised yellow wavy lines at hand height on a wall to indicate a corridor or hallway; orange circles with a ribbed texture in a grid pattern to identify the start or end of a stairway bannister).

The Sensory Vision team (Fae, Athelia, Laura, Issy and Sakshi) combined embroiderers, printers and a weaver who focused upon crafting textiles for an interactive multi-sensory interior space. The team took inspiration from sensory rooms, including primary research with Mencap Nottingham. Their experiential concept focused on 'having somewhere to escape to and relax in' as a response to informants' descriptions of day-to-day physical and emotional challenges. Sensory Vision's core focus involved empathizing with emotional and sensory overload, using a rich combination of gentle sensory cues to create playful, relaxing, adaptable and varied experiences (to be controlled by the end user). As such, the emotional experience of textiles was central to the team's design work, requiring them to explore with the informants 'felt qualities, images, feelings and emotions that ground our more abstract structures of meaning' (Johnson in Groth 2017: 5). In addition to exploring tactile qualities and associations, the team experimented with scented textiles by embedding smells such as lavender, jasmine, lemongrass and other essential oils (associated with relaxation) into the fabrics. The scents were omnipresent but the informants reported that many of the scents seemed stronger while they were interacting with the fabrics; this was partly due to directly smelling the samples by 


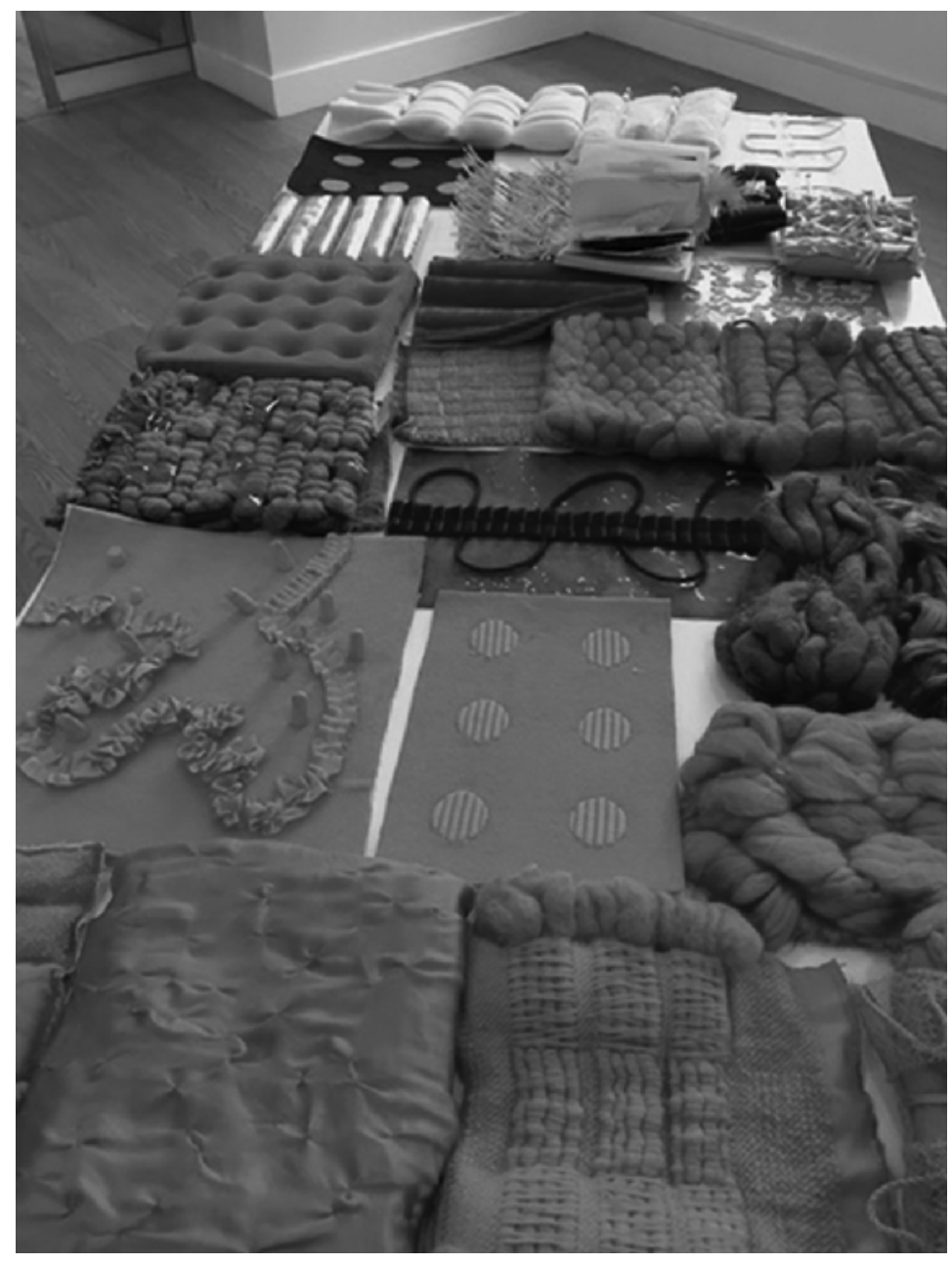

Figure 2: Selected samples made by the Textural Dialogue team. @ Kevin Hunt 2019. 
holding them to the nose but also through interactions that included squashing, squeezing, bouncing and stretching the fabrics.

Sensory Vision also experimented with creative forms of hand knitting, weaving and screenprinting (Figure 3), receiving direct tactile and other sensory feedback based on the informant's individual tastes and preferences. Adaptability and variation of experience were developed as part of the process, which included responding to informant preferences for slightly more weighty designs that felt 'dependable' and 'present'. Bold colour was used to enable high contrast and visibility. Selected designs also experimented with sound, embedding crinkly or rustling materials within softer knitted and woven exteriors to be both tactile and kinaesthetic. The use of scent was especially welcomed by the informants because it provided an additional level of sensory engagement that did not necessarily require haptic engagement or making use of limited sight (when tired).

The Inverted Environment team (Holly, Rhian, Rochelle, Kate and Sophia) of knitters and weavers adopted a product-led approach to their prototypes, taking inspiration from warnings and guidance found in the urban environment (such as hazard tape/signage) to which they added sensory aesthetic appeal beyond the basic functions of visual information. The group experimented extensively with materials, which became integral to the team's interactions with the informants (Figure 4) because certain material properties stimulated informants to suggest potential applications. This approach made strong use of tactile communication and expression through material properties, whereby the informants simultaneously sought for and started to give form to ideas by exploring and manipulating the material samples (Groth 2017: 52-42). Silicone featured heavily in their prototypes due to the dual properties of malleability combined with non-slip applications (staying in place on smooth surfaces such as tables, allowing other objects to be placed securely on top and retaining their place on curved surfaces such as the arm or headrest of an armchair). The weight of the silicone, when combined with knitted and woven textiles, was also considered 'reliable' and 'reassuring'.

Inverted Environment combined conventional techniques (such as knitting and princess pleating) with silicone, clay and e-textiles components. These approaches enabled the introduction of interactive elements, such as vibrating materials, intended to indicate the edge or end of a surface (such as a bannister or a table). The physical characteristics of silicone and puff binders (Figure 5), which were initially applied for their tactile qualities, were jointly identified by the team and informants as having an array of functional non-slip properties. This realization inspired the team to consider several product applications, including non-slip mats and vibrating floor sensors for the navigation of stairs and internal spaces, whereby textured surfaces could communicate both visually and haptically. The Inverted Environment concept engaged closely with the understanding that while experiential textiles are important to all, they are especially important to people who are visually impaired. The team took the theme of warnings and awareness within the urban environment and then amended and softened the tactile and visual messages for interior spaces to provide balance between comfort and a sense of security. 


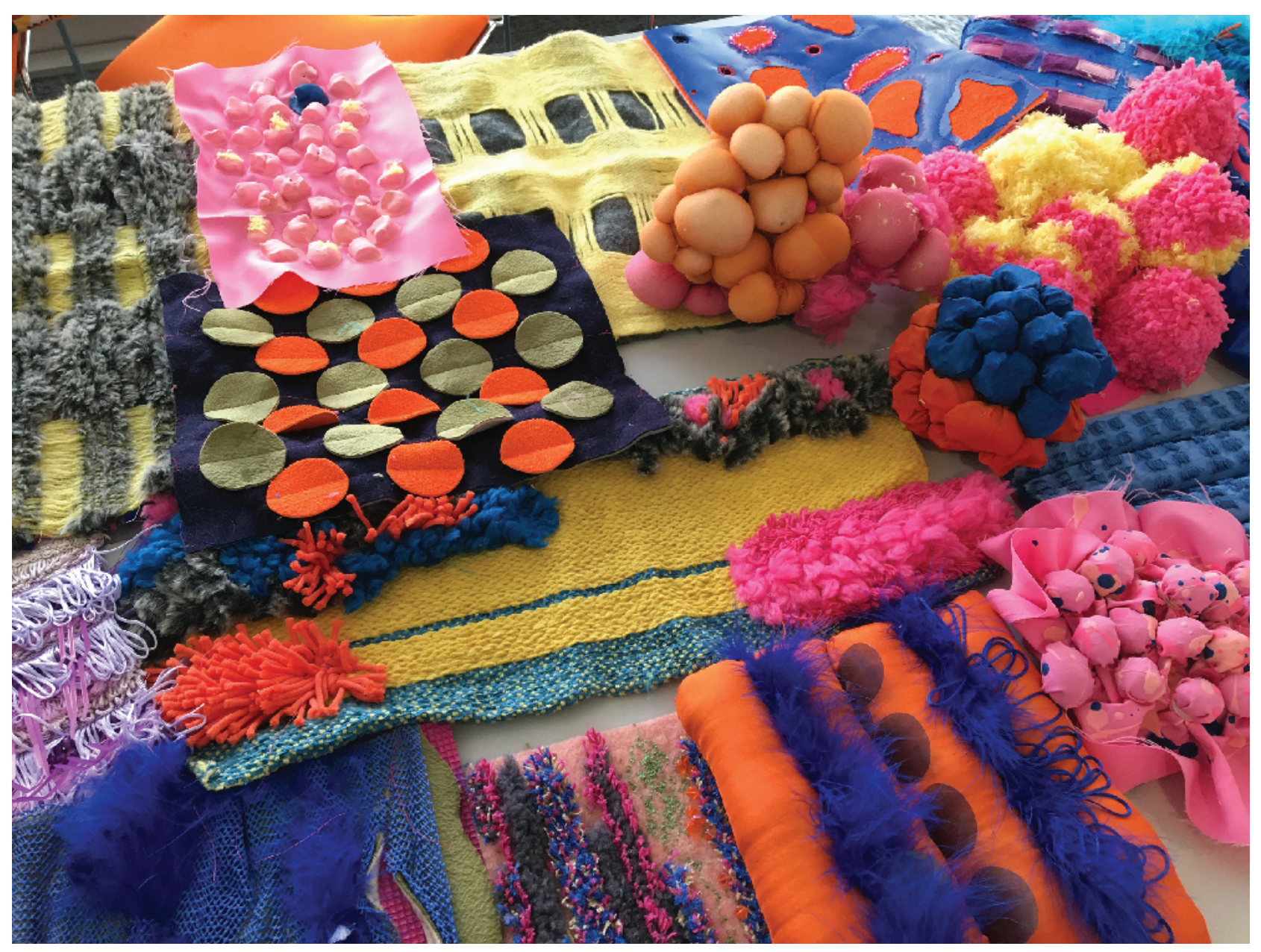

Figure 3: A selection of samples made by the Sensory Vision team. @ Kevin Hunt 2019. 


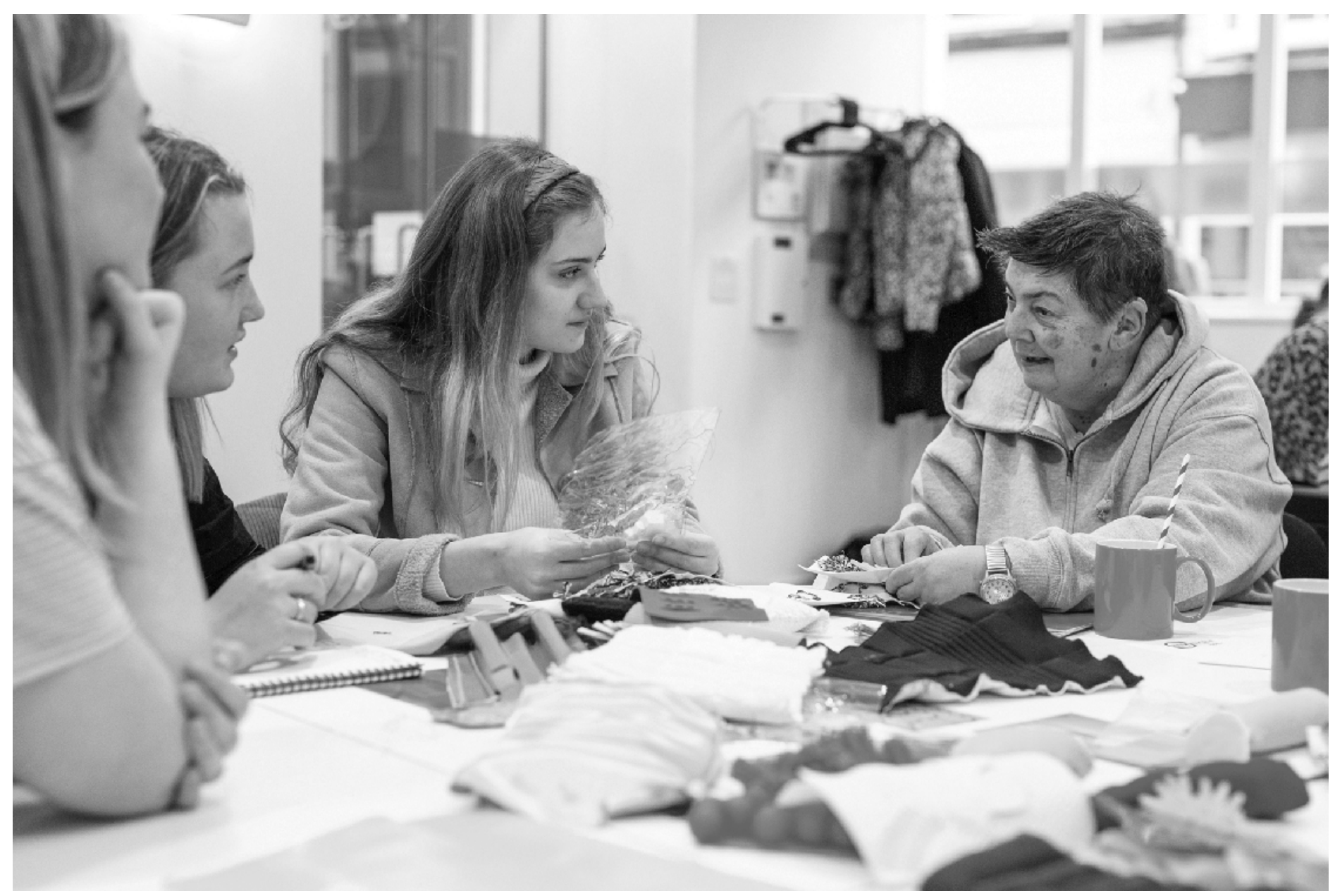

Figure 4: Informant, Carole, engaged in a descriptive and materials-based sensory stimuli session with participants, Dory, Hannah and Janna. @ NTU, photographer Mike Kane 2019. 


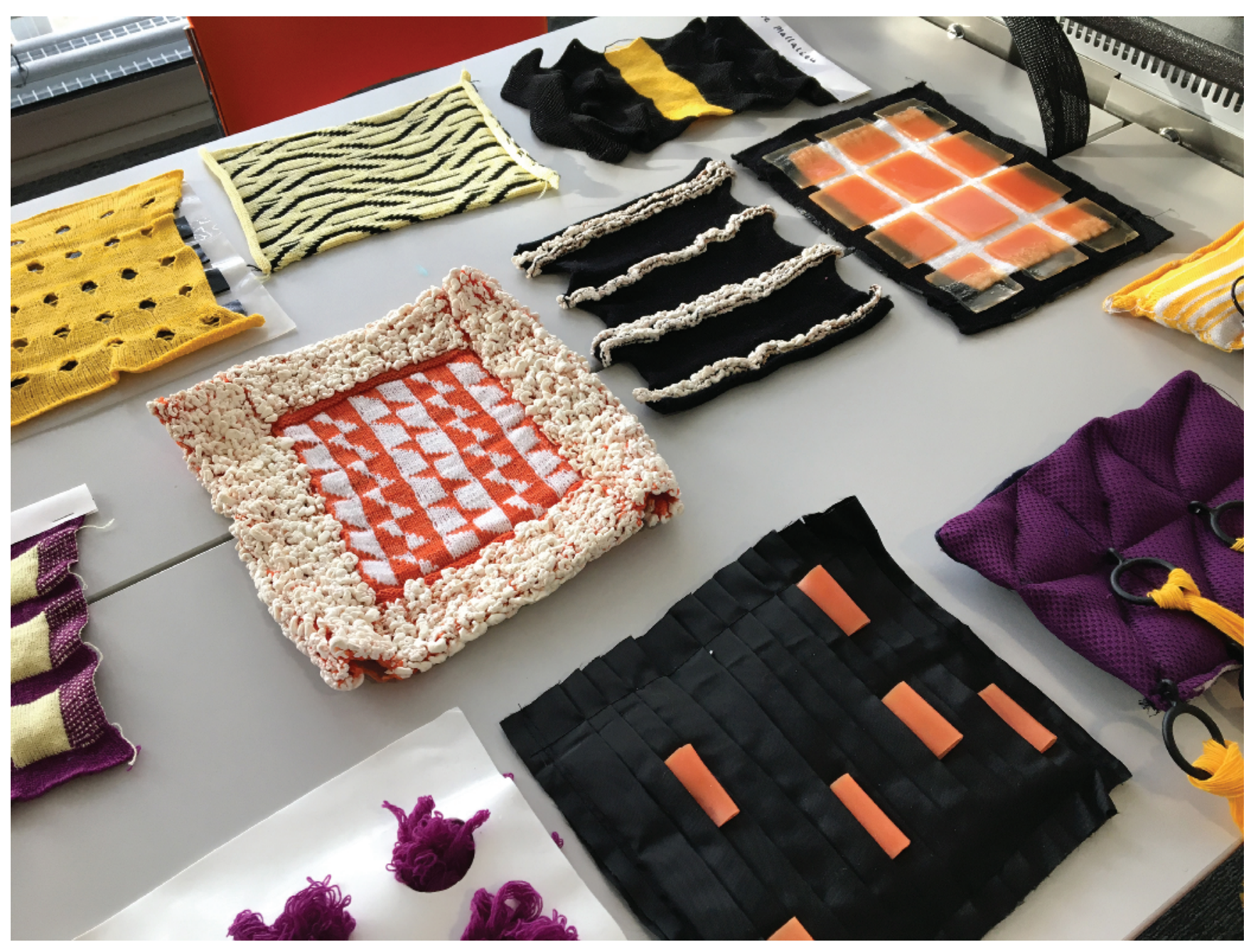

Figure 5: Selected samples made by the Inverted Environment team. ㄷ Kevin Hunt 2020. 


\section{Process, method and theory}

Table 1 provides an overview of how the project was organized, with events listed by date, description of activities, where the activities occurred, who was in attendance and the content/aim of each session.

The project was situated within human-centred design, with'design' understood (in this context) as part of the driving force of the creative thought process (Giacomin 2015: 607). The focus of the project was producing'physically intuitive' (2015: 610-12) textile prototypes for people who are visually impaired, whereby looking at the textiles may not reveal their potential application, which instead became apparent through physical engagement. The project drew inspiration from sensory design (Heywood 2017; Lupton and Lipps 2018), including empathic design processes (Mattelmaki et al. 2014; Suri 2003; Koskinen et al. 2003) and sensory ethnographic research methods (Pink 2015). As Koskinen and Battarbee state, '( $\mathrm{t}$ )he key to empathic design is an understanding of how the user sees, experiences and feels some object, environment or service' (2003: 45).

As a starting point for the project (event A), the participants (students) were invited to 'imagine' life with a severe or blind visual impairment by undertaking Sighted Guide training. This included discussion of facts and experiences relating to visual impairment; wearing 'sim specs' (Figure 6) to simulate the approximate visual limitations caused by cataracts, retinal and macular degeneration, right side/left side loss of vision and reduced visual acuity; and wearing blindfolds to experience being guided through both indoor and outdoor scenarios (Figure 7). These comparatively basic experiential insights into visual impairment produced numerous anecdotes of amended sensory processing through increased reliance upon hearing and touch. Based on the 'Designer's radar' (Koskinen and Battarbee 2003: 45), the participants then moved from an 'imagined' to an 'experienced' depth of context by engaging in observational and participatory sessions with the informants.

The observational and participatory sessions (events D and F) required learning directly from people who are visually impaired through semi-structured sensory ethnographic interviews (Figure 4); these interviews were conducted using a 'sensory stimuli' approach, whereby carefully chosen materials - in this case material samples and textile prototypes in progress - were used to invite responses and discussion (Pink 2015: 88). Drawing upon Sarah Pink's approach to 'emplaced' sensory ethnography - which seeks understanding about the relationship between 'body-mindenvironment' (2015: 28) - all sessions with informants were hosted at My Sight's city centre hub in Nottingham, which is a space where the informants felt comfortable, familiar, relaxed and 'at home'. These sessions also relied on selected aspects of social haptics (see Helen Keller National Center 2018), particularly 'environmental description' (Lahtinen et al. 2010), whereby the targets of description - the material samples and textile prototypes - were explored through verbal, tactile and (where appropriate) sound, smell and kinetic interactions (Lahtinen et al. 2010: 15). 


\begin{tabular}{|c|c|c|c|c|c|}
\hline Event & Date & Activity & Place & Attendees & Content/Aim \\
\hline A & $19 / 11 / 2018$ & $\begin{array}{l}\text { Setting the My Sight Project Brief } \\
\text { ( } 1 \text { hour) }\end{array}$ & NTU & $\begin{array}{l}\text { Full year group of students }+ \\
\text { NTU tutors }\end{array}$ & $\begin{array}{l}\text { Presentation of the My Sight project brief to } \\
\text { recruit up to } 16 \text { participants (students) }\end{array}$ \\
\hline B & $22 / 11 / 2018$ & $\begin{array}{l}\text { My Guide: Sighted Guide Training } \\
\text { delivered by My Sight } \\
\text { My Guide training was developed by } \\
\text { My Sight in partnership with Visionary } \\
\text { UK and Guide Dogs for the Blind UK } \\
\text { ( } 3 \text { hours) }\end{array}$ & NTU & 15 participants + NTU tutors & $\begin{array}{l}\text { Participants complete My Guide: Sighted Guide } \\
\text { Training and are awarded a Level } 1 \text { certificate } \\
\text { ('the capability to provide appropriate assistance } \\
\text { to a blind or partially sighted person to aid safe } \\
\text { negotiation of their environment with dignity and } \\
\text { promotion of independence') }\end{array}$ \\
\hline C & $\begin{array}{l}03 / 12 / 2018 \\
(\mathrm{AM})\end{array}$ & $\begin{array}{l}\text { Team Tutorials } \\
\text { ( } 2 \text { hours) }\end{array}$ & NTU & 15 participants + NTU tutors & $\begin{array}{l}\text { Presentation of team concept ideas in response to } \\
\text { the project brief }\end{array}$ \\
\hline $\mathrm{D}$ & $\begin{array}{l}\text { 03/12/2018 } \\
(\mathrm{PM})\end{array}$ & $\begin{array}{l}\text { Participants first meeting with } \\
\text { Informants ( } 3 \text { hours) }\end{array}$ & $\begin{array}{l}\text { My Sight City } \\
\text { Centre Hub }\end{array}$ & $\begin{array}{l}15 \text { participants }+9 \text { My Sight } \\
\text { informants }+ \text { NTU tutors + } \\
\text { My Sight staff, including } \\
\text { Support Workers }\end{array}$ & $\begin{array}{l}\text { Initial meeting to share concept ideas, material } \\
\text { samples, and descriptive engagement sessions; } \\
\text { semi-structured sensory ethnographic interviews } \\
\text { using sensory stimuli approach }\end{array}$ \\
\hline E & $14 / 01 / 2019$ & $\begin{array}{l}\text { Team Tutorials } \\
\text { ( } 2 \text { hours) }\end{array}$ & NTU & 15 participants + NTU tutors & Team concept development and progress check \\
\hline F & $21 / 01 / 2019$ & $\begin{array}{l}\text { Second (interim) Visit to My Sight }+ \\
\text { Team Tutorials } \\
\text { ( } 3 \text { hours) }\end{array}$ & $\begin{array}{l}\text { My Sight City } \\
\text { Centre Hub }\end{array}$ & $\begin{array}{l}15 \text { participants }+9 \text { My Sight } \\
\text { informants }+ \text { NTU tutors }+ \\
\text { My Sight staff, including } \\
\text { Support Workers }\end{array}$ & $\begin{array}{l}\text { Sharing prototypes for sensory feedback and } \\
\text { descriptive engagement sessions; semi-structured } \\
\text { sensory ethnographic interviews using sensory } \\
\text { stimuli approach; team concept development and } \\
\text { progress check }\end{array}$ \\
\hline G & $04 / 02 / 2019$ & $\begin{array}{l}\text { Live Project Final Presentations: } \\
\text { Enriching Society } \\
\text { ( } 2 \text { hours) }\end{array}$ & NTU & $\begin{array}{l}\text { My Sight CEO Michael } \\
\text { Conroy, My Sight Arts } \\
\text { Development Officer Jeanne } \\
\text { Roberts, My Sight Support } \\
\text { Worker (Claire) + } 15 \\
\text { participants + NTU Tutors }\end{array}$ & $\begin{array}{l}\text { Final presentation of project concepts and } \\
\text { prototypes for the three teams (handling and } \\
\text { feedback session): } \\
\text { - Textural Dialogue } \\
\text { - Inverted Environment } \\
\text { - Sensory Vision }\end{array}$ \\
\hline $\mathrm{H}$ & $22 / 03 / 2019$ & $\begin{array}{l}\text { Live Project Final Presentations: } \\
\text { Enriching Society } \\
\text { ( } 3 \text { hours) }\end{array}$ & $\begin{array}{l}\text { My Sight City } \\
\text { Centre Hub }\end{array}$ & $\begin{array}{l}15 \text { participants }+9 \text { My Sight } \\
\text { informants }+ \text { NTU tutors }+ \\
\text { My Sight staff, including } \\
\text { Support Workers }\end{array}$ & $\begin{array}{l}\text { Final presentation of project concepts and } \\
\text { prototypes for the three teams (handling, } \\
\text { feedback and social session): } \\
\text { - Textural Dialogue } \\
\text { - Inverted Environment } \\
\text { - Sensory Vision }\end{array}$ \\
\hline
\end{tabular}




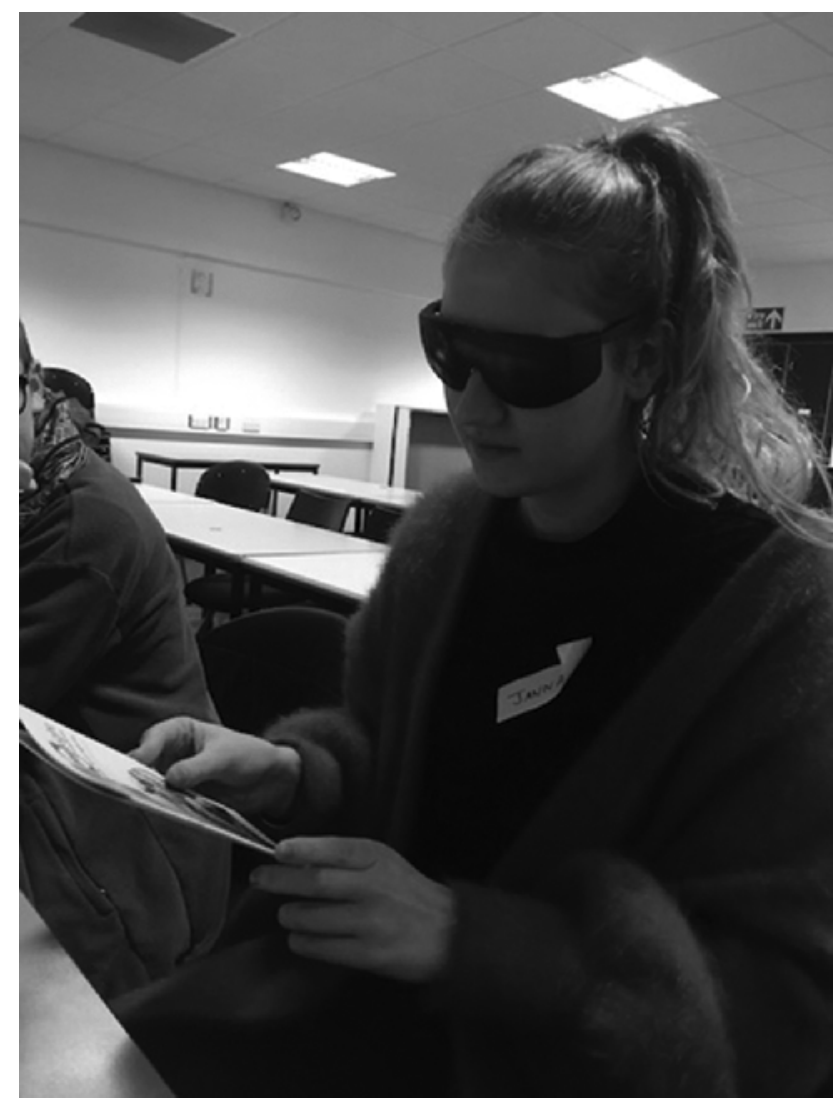

Figure 6: Participant, Janna, using 'sim specs' to approximate experiences of visual impairment. (C) Kevin Hunt 2018.

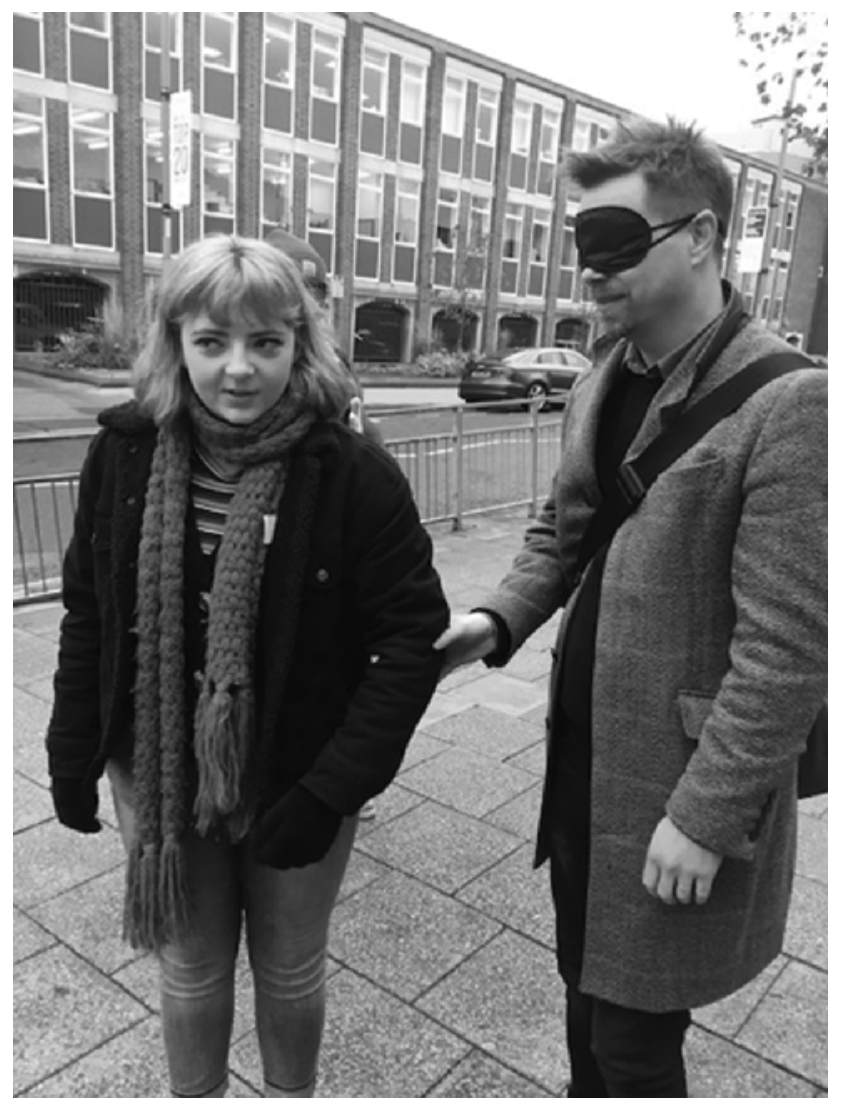

Figure 7: Sighted Guide training being undertaken by participant, Fae, and NTU tutor. (C) Kevin Hunt 2018, photographer Issy Murphy. 
An important consideration within environmental description is the visual literacy of the 'describer' (Lahtinen et al. 2010: 19). In this case, the participants (who were the describers) were often primarily visual learners in addition to being tactile makers, working with their hands daily. A significant theoretical basis for the project involved drawing upon shared 'tacit knowledge' (Polanyi 1958) of touch, as one aspect of embodied cognition (Groth 2017), to provide a sensory meeting point between two groups of people - the participants and the informants - who, through a combination of choice and necessity, consistently rely upon haptic experiences and embodied knowledge. Within the literature of sensory studies, Geurts' anthropological research has shown that culturated experiences shape our sensory perception $(2002,2005)$. In particular, Geurts progresses the idea of sensorial empathy and the capability for more fully embodied and inter-subjective understanding of others, including shared empathy and the 'mingling of sensibilities' between individuals (Geurts 2002, 2005: 168). Drawing upon Classen's 'sensory model' (1997: 402) and the concept of 'communal perceptual orientation' (Howes 2006: 114), the My Sight project found that foregrounding touch as a sensorial meeting point between participants and informants provided a basic form of shared perceptual orientation within the context of the project. Through this emphasis upon touch, the participants felt that they developed a meaningful level of sensorial empathy with the experiences of the informants - particularly in relation to understanding and selecting appropriate materials.

\section{Furthering the language of touch and future recommendations}

One recurring aspect of participant feedback on the project echoed the findings of Fayen d'Evie and Georgina Kleege's investigations into 'haptic criticism and tactile dialogue' (2018). In particular, d'Evie and Kleege encouraged awareness of the 'language of touch' (Haug 2016), brought into focus through the different kinds of touching used to engage with particular objects, surfaces and textures, which included 'tracing, pinching, stroking, manipulating, folding, tapping, grasping, shaking', and 'the different body parts enlisted to do it - fingertips, palms, whole hand, forearms, whole arms, whole body' (d'Evie and Kleege 2018). In the context of the My Sight project, the main kinds of touch used by both informants and participants included dabbing, holding, pressing, rubbing, stroking, wrapping, squeezing, hugging, draping, teasing, tapping, bouncing, folding and manipulating. The body parts used focused on the forehead, cheeks, nose (especially for scented fabrics), lips, whole face, shoulders and neck, forearms (back and front), back of hand, back of the fingers, palm, fingertips, whole hand, thighs, feet and toes. Also the varied associations and sensations included comfort, security, stress relief, relaxation, calming, softness, firmness, density, weight, tingling, tickling, pleasure and a range of more abstract associations and personal memories of people and places evoked by scent.

The high importance of the language of touch emerged throughout the course of the project, which integrated tutorials and progress checks (events C, E and F) between the observation and 
participatory sessions at My Sight. The language of touch was also highlighted in reflective feedback gathered after the project was complete. A future project of this nature would find it valuable to catalogue the language of touch from the beginning, including associations between materials and preferred types kinds of touch and the haptic sensations that they produce. Another important feature of the project was a description of the term 'grounded', which was used frequently by the informants to refer to their use of touch - including in relation to specific, sometimes personal, objects - to provide self-stimulated comfort, reassurance and/or to help maintain mental focus on the surrounding environment, including following conversations or activities (Hunt 2019).

From a textile design perspective, the participants developed and extended their existing knowledge of materials and the crafting process. A number of participants commented that their previous experiences developing design concepts focused on commercial outcomes, which had tended to focus strongly on visual aesthetics, and so the My Sight project had encouraged them to reassess and reconsider the importance of the physical and material properties of their designs paying attention to the entirety of the crafting and design process, including considering the whole cloth and how it would be experienced from a range of sensory perspectives. The participants also commented upon the positive impact that the project had on them, working directly with informants to craft designs intended to be purposeful and aesthetically pleasing (in modes that looked beyond the visual).

Participant reflection included three main considerations for future projects:

1. Consider every element of the fabric: front, back, sides, corners, loose threads, and so on because the emphasis on haptic engagement (primarily touch) requires close attention to detail and finishing.

2. Consider the weight distribution of the fabric and materials in the final sample. Weight provided comfort and reliability in hand-held textiles and different weights helped many of the informants to feel'grounded'.

3. Consider the visual aspects of the design, both from the perspective of high contrast and visibility for people who are visually impaired, and consider the appearance of the textiles to people who are sighted (so that the designs are not overtly specialized to the extent that they become signifiers of disability). Focus on highly contrasting colours that have visual aesthetic appeal and consideration of tactile aesthetic appeal.

Other specific recommendations that emerged from the project process and methods include the strong impact of the Sighted Guide training on the participants, notably from their experiences of being outdoors while blindfolded and their awareness of amended sensory processing. While the experiences were highly limited in terms of simulating the reality of living with a visual impairment, it set in place the concept of sensorial empathy from very early in the project and that underpinned 
the observational and participatory sessions that followed. The focus on material samples and prototypes, centred around touch-led sensory engagement, was also highly effective in providing sensory insights and aiding understanding of the informant's experiences and needs. In an ideal situation, with a much longer project, the notion of emplaced ethnography would have been expanded to include the possibility of visiting informants within their home settings. Nevertheless, the context of My Sight as a secure and familiar 'home from home' environment provided the right setting for relaxed and open discussions and interactions between participants and informants. As a final note, the terms 'participants' and 'informants' (whilst important to explain the roles undertaken within the project) do not fully communicate the sense of knowledge transfer and creative dialogue that took place. In an extended project, this form of knowledge transfer and shared sensibility relating to touch would be more fully explored, including greater engagement with ongoing research into embodied cognition (Groth 2017).

\section{References}

Bristow, M. (2012), 'Continuity of touch - textile as silent witness', in J. Hemmings (ed.), The Textile Reader, London: Berg, pp. 44-52.

Classen, C. (1997), 'Foundations for an anthropology of the senses', International Social Science Journal, 49:153, pp. 401-12.

- (2002), The Color of Angels: Cosmology, Gender and the Aesthetic Imagination, London: Routledge.

_ (2012), The Deepest Sense: A Cultural History of Touch, Chicago, IL: University of Illinois Press.

d'Evie, F. and Kleege, G. (2018), 'The gravity, the levity: Let us speak of tactile encounters', Disability Studies Quarterly, 38:3, http://dsq-sds.org/article/view/6483/5090. Accessed 9 January 2019.

Geurts, K. (2002), Culture and the Senses: Bodily Ways of Knowing in an African Community, Berkeley: University of California Press.

- (2005), 'Consciousness as "Feeling in the Body": A West African theory of embodiment, emotion and the making of mind', in D. Howes (ed.), Empire of the Senses: The Sensual Culture Reader, Oxford: Berg, pp. 164-78.

Giacomin, J. (2015), 'What is human centred design?', The Design Journal, 17:4, pp. 606-23.

Groth, C. (2017), Making Sense through Hands: Design and Craft Practice Analysed as Embodied Cognition, Doctoral dissertation, Helsinki: Aalto Arts Books.

Haug, K. (2016), 'Touching to see: Haptic description and 21st century visuality', LXAQ International Art and Culture, 1, http://sfaq.us/2016/10/touching-to-see-haptic-description-and-21st-centuryvisuality/. Accessed 6 June 2018. 
Hayhoe, S. (2008), Arts, Culture and Blindness: A Study of Blind Students in the Visual Arts, Youngstown, NY: Teneo Press.

Helen Keller National Center (2018), 'Introduction to haptics', Helen Keller National Center, December, https://www.helenkeller.org/hknc/lesson/chapter-1-overview-haptics. Accessed 15 December 2018.

Hemmings, J (ed.) (2012), The Textile Reader, London: Berg.

Heywood, I. (ed.) (2017), Sensory Arts and Design, London: Bloomsbury.

Howes, D. (1991), The Varieties of Sensory Experience: A Sourcebook in the Anthropology of the Senses, Toronto: University of Toronto Press.

— (ed.) (2005), Empire of the Senses: The Sensual Culture Reader, Oxford: Berg.

— (2006), 'Charting the sensorial revolution', The Senses and Society, 1:1, pp. 113-28.

Howes, D. and Classen, C. (2014), Ways of Sensing: Understanding the Senses in Society, London: Routledge.

Hunt, K. J. (2018), 'Eyes, sight and the senses on film and in fashion: Crossmodal correspondences and sensorial empathy between Lars von Trier's Dancer in the Dark (2000) and Johan Ku's "Selma" Collection S/S (2014)', Fashion Theory, 22:1, pp. 31-67.

— (2019), 'LAPVI and LIVE: Reflections on two collaborative projects between my sight and NTU art and design', Learning Aesthetics from People who are Visually Impaired (LAPVI) Symposium, My Sight Nottinghamshire City Centre Hub, Nottingham, 20 September.

Jay, M. (1993), Downcast Eyes: The Denigration of Vision in Twentieth-Century French Thought, Berkeley: University of California Press.

Kleege, G. (2018), More Than Meets the Eye: What Blindness Brings to Art, Oxford: Oxford University Press.

Koskinen, I. and Battarbee, K. (2003), 'Introduction to user experience and empathic design', in I. Koskinen, K. Battarbee and T. Mattelmaki (eds), Empathic Design: User Experience in Product Design, Edita: IT Press, pp. 37-50.

Koskinen, I., Battarbee, K. and Mattelmaki, T. (eds) (2003), Empathic Design: User Experience in Product Design, Edita: IT Press.

Lahtinen, R., Palmer, R. and Lahtinen, M. (2010), Environmental Description for Visually and Dual Sensory Impaired People, Nottingham: A1 Management UK.

Leonard, D. and Rayport, J. F. (1997), 'Spark Innovation through empathic design', Harvard Business Review, November-December, pp. 103-13. 
Lupton, E. and Lipps, A. (2018), The Senses: Design Beyond Vision, New York: Cooper Hewitt, Smithsonian Design Museum and Princeton Architectural Press.

Marks, L. U. (2000), The Skin of the Film: Intercultural Cinema, Embodiment, and the Senses, Durham and London: Duke University Press.

Mattelmaki, T., Vaajakallio, K. and Koskinen, I. (2014), 'What happened to empathic design?', Design Issues, 30:1, pp. 67-77.

Pink, S. (2015), Doing Sensory Ethnography, 2nd ed., London: Sage.

Polanyi, M. (1958), Personal Knowledge: Towards a Post-Critical Philosophy, London: Routledge \& Kegan Paul Ltd.

Serres, M. (2016), The Five Senses: A Philosophy of Mingled Bodies (trans. M. Sankey and P. Cowley), London: Bloomsbury.

Suri, J. F. (2003), 'Empathic design: Informed and inspire by other people's experience', in I. Koskinen, K. Battarbee and T. Mattelmaki (eds), Empathic Design: User Experience in Product Design, Edita: IT Press, pp. 51-58.

WHO (2019), 'Blindness and visual impairment', World Health Organisation, 8 October, https://www.who.int/news-room/fact-sheets/detail/blindness-and-visual-impairment. Accessed 1 November 2019.

\section{Suggested citation}

Hunt, Kevin, Piper, Anna and Worker, Georgie (2020), 'The importance of sensorial empathy and the language of touch when crafting textiles for people who are visually impaired', Craft Research, 11:1, pp. 57-77, https://doi.org/10.1386/crre_00015_1

\section{Contributor details}

Dr Kevin Hunt is senior lecturer in design, culture and context at NTU, where he is also the postgraduate research tutor for the School of Art and Design. His research relates to culture, the senses and design with a particular interest in eyes, sight and visual impairment. Kevin led the British Academy-funded project 'Learning Aesthetics from People who are Visually Impaired' (2018). His research publications include an article about crossmodality and sensory transfer for Fashion Theory and articles and reviews for The Senses and Society, Afterimage, Journal of American Studies, Eye Magazine and The Conversation.

Contact: School of Art \& Design, Nottingham Trent University, 50 Shakespeare Street, NG1 4FQ, UK.

E-mail: kevin.hunt@ntu.ac.uk 
Dr Anna Piper is a senior lecturer in textile design and design, context and culture at NTU. Anna's practice-led Ph.D. (2019) Material Relationships: The Textile and the Garment, the Maker and the Machine investigates 3D/composite garment and pattern weaving, integrating hand and digital jacquard technologies. Her research and craft/ design interests include zero-waste, functional textiles, embodied knowledge and innovation. Anna is undertaking empirical research in Guatemala, supported by the Global Challenges Research Fund (AHRC, UK), and has published in the journal of Textile Design Research and Practice, the Design Research Society and co-edited Cumulus Soft Landing: Fashion and Textile Education (2018).

Contact: School of Art \& Design, Nottingham Trent University, 50 Shakespeare Street, NG1 4FQ, UK.

E-mail: anna.piper@ntu.ac.uk

으 https://orcid.org/0000-0002-4334-7878

Georgie Worker is a lecturer in textile design in at Nottingham Trent University. Georgie is a printed textile/ surface design specialist who has worked within industry designing and manufacturing specialist wall coverings and textile collections for both domestic interior and contract markets. Moving into academia in 2017 Georgie is keen to bridge the gap between academia and industry championing live projects, external competitions and is also currently the vice chair for Society of Dyers and Colourists midlands region. Her teaching and research interests include curriculum design centred around building community, inclusive practice and flexible learning.

Contact: School of Art \& Design, Nottingham Trent University, 50 Shakespeare Street, NG1 4FQ, UK.

E-mail: georgie.woker@ntu.ac.uk

(C) https://orcid.org/0000-0002-1225-437X

Kevin Hunt, Anna Piper and Georgie Worker have asserted their right under the Copyright, Designs and Patents Act, 1988, to be identified as the authors of this work in the format that was submitted to Intellect Ltd. 


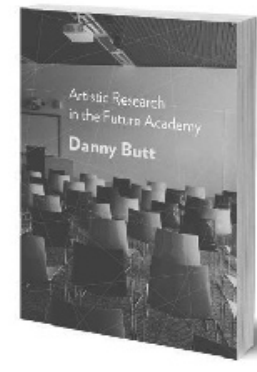

\section{Artistic Research in the Future Academy}

By Danny Butt

ISBN 978-1-78320-790-9

180 pp |£72, \$96

Hardback | $170 \times 230 \mathrm{~mm}$

Published Fall 2017

The rapid growth of doctoral-level art education challenges traditional ways of thinking about academic knowledge, and yet, Danny Butt argues in this book, the creative arts may also represent a positive blueprint for the future of the university. Synthesizing institutional history with aesthetic theory, Artistic Research in the Future Academy reconceptualizes the contemporary crisis in university education toward a valuable renewal of creative research.

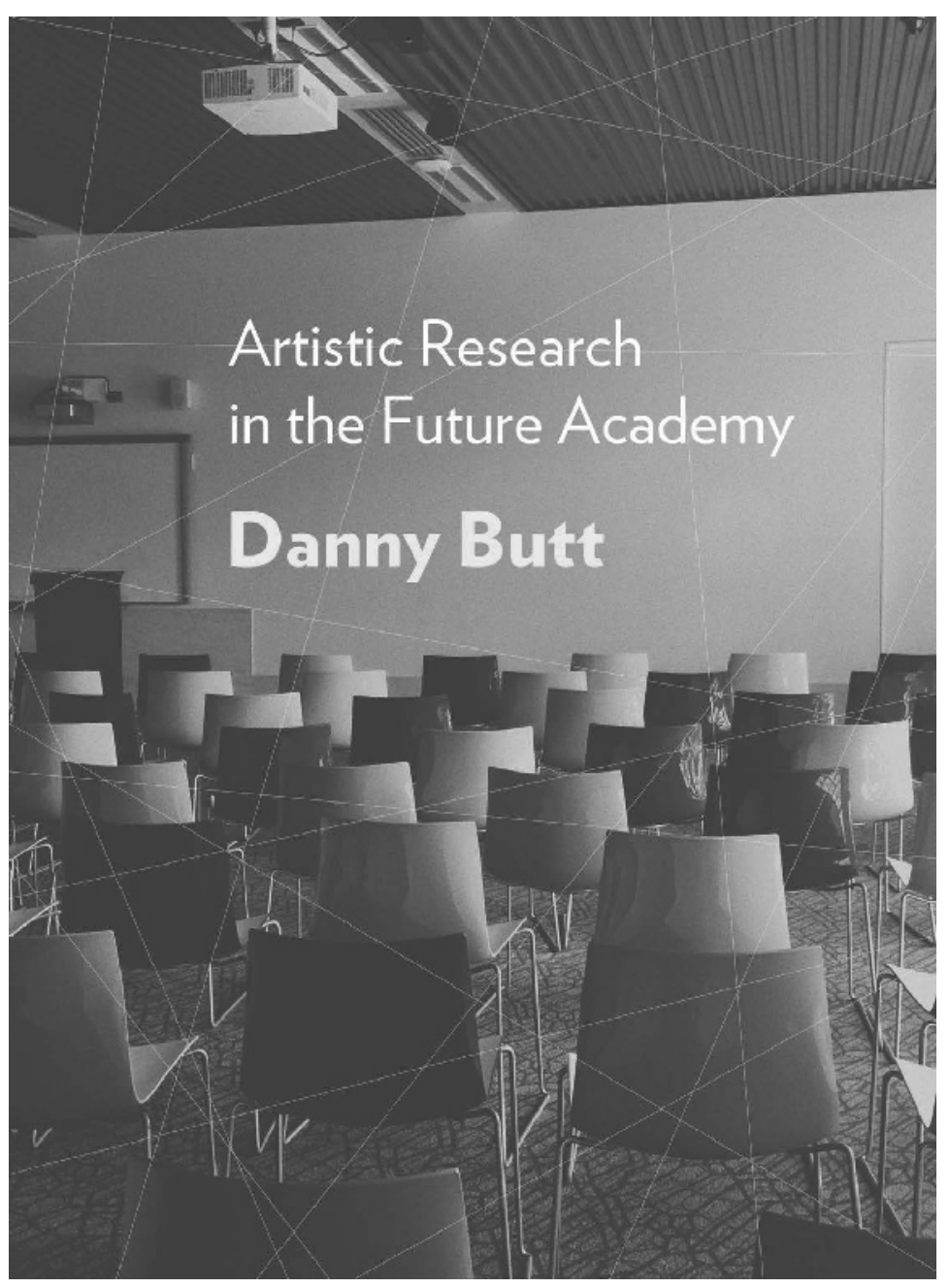

